\title{
Aprendizagem: processos psicológicos e o contexto social na escola
}

\author{
Fabiano Koich Miguek
}

Boruchovitch, E., \& Bzuneck, J. A. (Orgs.). (2004). Aprendizagem: processos psicológicos e o contexto social na escola. Petrópolis, RJ: Vozes, 282 p.

Para que a escola possa cumprir seu papel de desenvolver ao máximo o aprendizado dos alunos, é necessário conhecer como a aprendizagem se processa, ou seja, de que maneira o aluno aprende, e também quais os fenômenos que o influenciam. O livro organizado por Evelyn Boruchovitch e José Aloyseo Bzuneck reúne nove artigos atuais e concernentes à Psicologia Educacional, que buscam lançar luz sobre diferentes visões da área.

No primeiro capítulo, chamado Aprendizagem por processamento da informaşão: uma visão construtivista, José Aloyseo Bzuneck expõe a ótica construtivista do modelo de processamento de informação. A nova abordagem concentra-se apenas no funcionamento cognitivo, explicando a atividade mental do aluno individualmente. $\mathrm{O}$ autor descreve o fluxo da informação, explicando os papéis e limitações dos tipos de memória que selecionam a entrada de informação do ambiente, processam as informações, operam e codificam o novo conhecimento associando-o a um já existente, para então armazená-lo de maneira organizada e poder recuperá-lo posteriormente. Esse esquema é usado para explicar a incapacidade de alguns alunos de focar a atenção, descrevendo estratégias adequadas e inadequadas tanto de professores quanto de alunos no processo de aprendizagem.

Evelyn Boruchovitch, no segundo capítulo, $A$ auto-regulação da aprendizagem e a escolarização inicial, revê o conceito de auto-regulação em diversas abordagens teóricas, inclusive do processamento de informação, para expor a importância da metacognição desde a infância e, especialmente no ensino fundamental, para desenvolver estratégias de autocontrole. A autora cita pesquisas que demonstram que atrasos no desenvolvimento metacognitivo estão relacionados a baixo desempenho escolar, sugerindo estratégias motivacionais que promovam o desenvolvimento da auto-regulação, responsabilizando $\mathrm{o}$ aluno pela sua aprendizagem.

O terceiro capítulo, $A$ aprendizagem por meio de jogos: uma abordagem cognitivista, escrito por Maria Aparecida Mezzalira Gomes e Evely Boruchovitch, apresenta os benefícios de se utilizarem jogos com alunos, que podem servir tanto para fins de diagnóstico e intervenção, quanto para auxiliar a criança a auto-avaliar seu desempenho e desenvolver a auto-regulação de seus processos cognitivos e afetivos, o que será útil não apenas na escola, mas também em seu desenvolvimento profissional. Utilizando como referência a teoria do processamento de informação, as autoras demonstram que os desafios do jogo são representativos das exigências da vida real, portanto, seu uso tem fins de aprendizagem.

O quarto capítulo, intitulado $A$ importância da compreensão de leitura para a aprendizagem de universitários, de Acácia Aparecida Angeli dos Santos e Katya Luciane de Oliveira, apresenta a leitura como importante via de comunicação entre sujeito e sociedade. Destacando a visão cognitivista no entendimento do processo de aprendizagem, as autoras revisam diversos estudos explicativos das habilidades mentais e sugerem o teste de Cloze como instrumento de avaliação da compreensão de leitura. Criticam, ainda, a reduzida habilidade de estudantes universitários em compreender textos científicos e desenvolver argumentos críticos, resultado da insatisfatória escolarização, destacando a responsabilidade das universidades no processo de formação profissional.

O quinto capítulo foi escrito por Sonia Regina Loureiro e Paula Cristina Medeiros e se chama Criancas com dificuldades de aprendizagem: vulnerabilidade e proteção associadas à auto-eficácia e ao suporte psicopedagógico. As autoras utilizam a abordagem desenvolvimentista para conceituar situações de risco no contexto escolar e apresentar a dificuldade de aprendizagem como fator de vulnerabilidade no desenvolvimento infantil. Destaca-se a autopercepção do aluno em relação à sua auto-eficácia como determinante do rendimento acadêmico, apontando uma pesquisa cujo resultado incentiva o uso de programas de intervenção psicopedagógica em crianças com baixo desempenho escolar.

No sexto capítulo, Necessidade de pertencer: um motivo bumano fundamental, Sueli Edi Rufini Guimarães mostra a escola como um importante ambiente de interação com outras pessoas, especialmente na adolescência, quando surgem mais dificuldades ligadas ao social, e apresenta elaborações teóricas sobre a necessidade humana de pertencer, levando em consideração a percepção da qualidade do vínculo com os outros. A autora apresenta pesquisas que demonstram a importância da figura do professor, e também a relação entre o sentimento de pertencer e melhor qualidade de vida, tanto escolar quanto pessoal e social.

\footnotetext{
* Endereço para correspondência:

E-mail: fabianokm@yahoo.com
} 
Carolina Lisboa e Sílvia Helena Koller, no sétimo capítulo, Interações na escola e processos de aprendizagem: fatores de risco e proteção, retratam a escola não apenas como um ambiente de aquisição de conhecimentos, mas também de desenvolvimento social para os jovens. Criticando a maior ênfase da Psicologia Educacional nos aspectos cognitivos dos alunos, as autoras utilizam a Teoria dos Sistemas Ecológicos para também entender a qualidade das interações com professores e pares, que podem gerar fatores de proteção ou situações de risco, como a vitimização.

Em Interaşão social, cooperaşão e aprendizagem, oitavo capítulo, Fermino Sisto, numa abordagem piagetiana que considera a interação social fundamental para a aprendizagem, conceitua dois tipos de conflito: cognitivo e sociocognitivo. Para ambos, o autor apresenta a definição dos construtos e suas influências nas situações de aprendizagem, assim como suas limitações, comentando os resultados das pesquisas desenvolvidas no Brasil, questionando, inclusive, a metodologia de algumas delas, e expondo algumas questões pertinentes que permanecem em aberto.

No nono e último capítulo, Aprendizagem escolar e contextos competitivos, José Aloyseo Bzuneck e Sueli Edi
Rufini Guimarães expõem diversas situações no ambiente escolar, em que a competição é estimulada pelos professores ao comparar o desempenho de alunos, ainda que a intenção tenha sido benéfica. Os autores citam pesquisas que estudam os efeitos desse contexto na autopercepção das habilidades, na auto-estima e na motivação dos alunos, e também nas estratégias que eles usam para lidar com isso. Revendo abordagens teóricas que explicam esse fenômeno, sugerem-se alguns procedimentos mais eficazes para ser usados por professores.

Os capítulos que compõem essa obra tomam o cuidado de explicar detalhadamente os conceitos de que fazem uso, revendo o arcabouço teórico da Psicologia Educacional e citando pesquisas pertinentes, recentes e nacionais. Além de apontar a adequação ou inadequação de estratégias de aprendizagem, tanto de professores quanto de alunos, os autores sugerem novos procedimentos, sejam de intervenção, sejam de prevenção, que podem ser adotados pela instituição educacional. Por isso, essa obra é recomendada aos profissionais envolvidos com o contexto escolar, sejam eles professores, educadores, psicopedagogos ou psicólogos.

Sobre o autor:

Fabiano Koich Miguel é psicólogo, especialista em Psicologia do Trânsito e mestrando em Psicologia pela Universidade São Francisco. 